\title{
Selecting a Condition Monitoring System for Enhancing Effectiveness of Power Transformer Maintenance
}

\author{
Hernandez, Maria Del Oilar Coli, University of Manchester \\ Labib, A., University of Portsmouth
}

\begin{abstract}
This paper aims to propose a model for assisting in the decision making process for acquiring a condition monitoring system for an oil-immersed power transformer in order to improve its maintainability. The proposed model is based on the Analytic Hierarchy Process (AHP). The assessment was performed by pairwise comparisons, and a sensitivity analysis (what if analysis) was used to identify the implications of changing the criteria weights. In order to select the criteria and alternatives a search was conducted for the power transformer failure modes, monitored parameters and condition monitoring technologies. The proposed model provides a structured solution for a complex problem: deciding the best combination of technologies for condition monitoring of power transformers. The power transformer is an asset where the most appropriate maintenance strategy for it is Condition Based Maintenance (CBM). In order to improve its maintainability is recommendable to improve its testability and diagnosability. For achieving this goal, the maintenance personnel have to decide the best combination of technologies for condition monitoring. The methodology developed can assist the decision makers to select the most appropriate cost-benefit strategy. The paper presents a structured and generic method of selecting the most appropriate condition monitoring system for power transformers.
\end{abstract}

Keywords: Maintainability, Testability, Condition Monitoring, Analytic Hierarchy Process, Decision Making Grid, Cost-Benefit Analysis, and Power Transformer.

\section{INTRODUCTION}

Electricity is widely considered as an invaluable good in humanity development. Currently its production, transmission and distribution are not only committed with the local market satisfaction, but with a high quality and clean production, being environment friendly, safe, reliable and efficient for those who are behind these processes and for its final end-users. Operationally, the electric utility sector is divided into three main processes: generation, 
transmission and distribution. The first process refers to the power plants in their multiple varieties: hydro, thermo, nuclear, etc. where the main function is to generate electricity. The second process, of transmission, refers to major electric substations and lines across the territory for stepping-up the voltage and transmitting the electricity generated to distribution centres. The third process, of distribution, consists of minor electric substations and lines for stepping-down the voltage of the system and delivering the service to end users. In the three processes, the power transformer is a very critical asset despite of its very low failure rate because of the potential impact that a failure could have in terms of safety, environment, production and cost. Its main function is to step-up or step-down to adequate voltage values of the electricity to allow its transmission and distribution. There are many types of transformers; this paper refers to oil-immersed large power transformers.

Usually, a country possesses a large population of power transformers and it is in the owners' interest to get the most out of them with high levels of safety and availability and minimum costs. Also, equipment is getting older, there are fewer experts to manage the current large population of power transformers, and there is more pressure from the top management to be more effective and efficient in maintaining them (CIGRE \#227, 2003). For those reasons and because more diagnostic and techniques are becoming available, on-line monitoring of power transformers and associated accessories is becoming an essential process of electric utilities (IEEE-STD-C57.143, 2012). Although there is high condition monitoring (CM) awareness for improving maintainability of the power transformers, most electric utilities have not fully implemented this approach on their facilities. There are many reasons causing this situation, but the lack of experts and effective diagnostic tools, and the difficulty of deciding the most cost-effective alternative for implementing a CM system are the most significant in the opinion of the authors.

This paper presents a model that will assist decision makers to determine the approach to monitoring conditions of a power transformer that will optimize effectiveness of condition based maintenance. This paper is divided into seven sections as follows: Section 2 presents a brief review of existing literature related to maintainability and the tools used in the paper: Decision Making Grid (DMG), and Analytic Hierarchy Process (AHP). Section 3 describes the power transformer and the different reasons for failure and their impact. The recommended parameters to be monitored and the available technologies according to standards are included. Section 4 covers a brief discussion regarding the current status of the condition monitoring as part of the current maintenance strategy. The decision making grid (DMG) is 
used for confirming that the recommended maintenance strategy for a transformer is Condition Based Maintenance (CBM). The reasons that prevent electric utilities from using $\mathrm{CM}$ are identified in this section. Section 5 includes the main issues to be considered for improving the maintainability of the transformer, specifically the element of testability, which is the main objective of the CM systems. Section 6 presents the proposed model for supporting the decision making process of selecting the most cost-effective strategy for monitoring a power transformer. The AHP is used and a sensitivity analysis is presented. The strengths and limitations of the proposed approach are discussed. Section 7 draws the conclusions of the paper.

\section{LITERATURE REVIEW}

\subsection{Maintainability}

Maintainability is a design characteristic that refers to "the measures taken during the development, design, and installation of a manufactured product that reduce required maintenance, man-hours, tools, logistic cost, skill levels, and facilities, and ensure that the product meets the requirements for its intended use" (Dhillon, 1999).

The main measures of the previous definition are: standardization, interchangeability, maintenance frequency, modularization, simplification, accessibility, identification, visibility, testability, human factors, and safety factors (Dhillon, 1999).

The element of maintainability that will be discussed in this paper is Testability. As stated in IEEE-STD-1522 (2004), testability was defined in MIL-STD-2165 as "a design characteristic which allows the status (operable, inoperable, or degraded) of an item to be determined and the isolation of faults within the item to be performed in a timely manner". However, in the IEEE standard the definition is complemented by the term diagnosability, defined as "the degree to which faults within a system can be confidently and efficiently identified'. By using sensors and performance monitoring systems, one can increase the testability level of equipment.

\subsection{DMG}


The Decision Making Grid (DMG) was introduced and improved by Labib (1998, 2004, 2014) to provide a tool for developing a maintenance programme by using the information on the Computerized Maintenance Management System (CMMS), which is not being used for making decisions.

The methodology consists of three steps: criteria analysis, decision mapping, and decision support. In step 1, the worst performing machines in terms of frequency of failure and downtime due to failure are identified. These two separate lists are then divided in three sections: high, medium and low. Suggestions for setting the thresholds between classifications have been made by Fernandez et al (2003), and Tahir et al (2008). Step 2 consists of mapping the machines in the DMG, which is shown in Figure 1. In step 3, the suggested action is identified according to the location of the machine on the grid. The different locations on the grid can be summarised as follows:

1. OTF (Operate to Failure). Keep doing the best practices

2. CBM (Condition Based Maintenance). Apply this approach to machines with high reliability, but great impact on downtime when a failure occurs.

3. SLU (Skill Level Update). Train operators to perform this maintenance.

4. DOM (Design Out Maintenance). Apply this approach to the most critical machines, those that fail frequently and for long periods.

5. FTM (Fixed Time Maintenance). Review the indicated element of your preventive maintenance routines: Who? \& When? (Easy elements) and How? and What? (Difficult elements).

The ideal status for all machines is the OTF block; that is the intention of the blue arrows on the grid. 


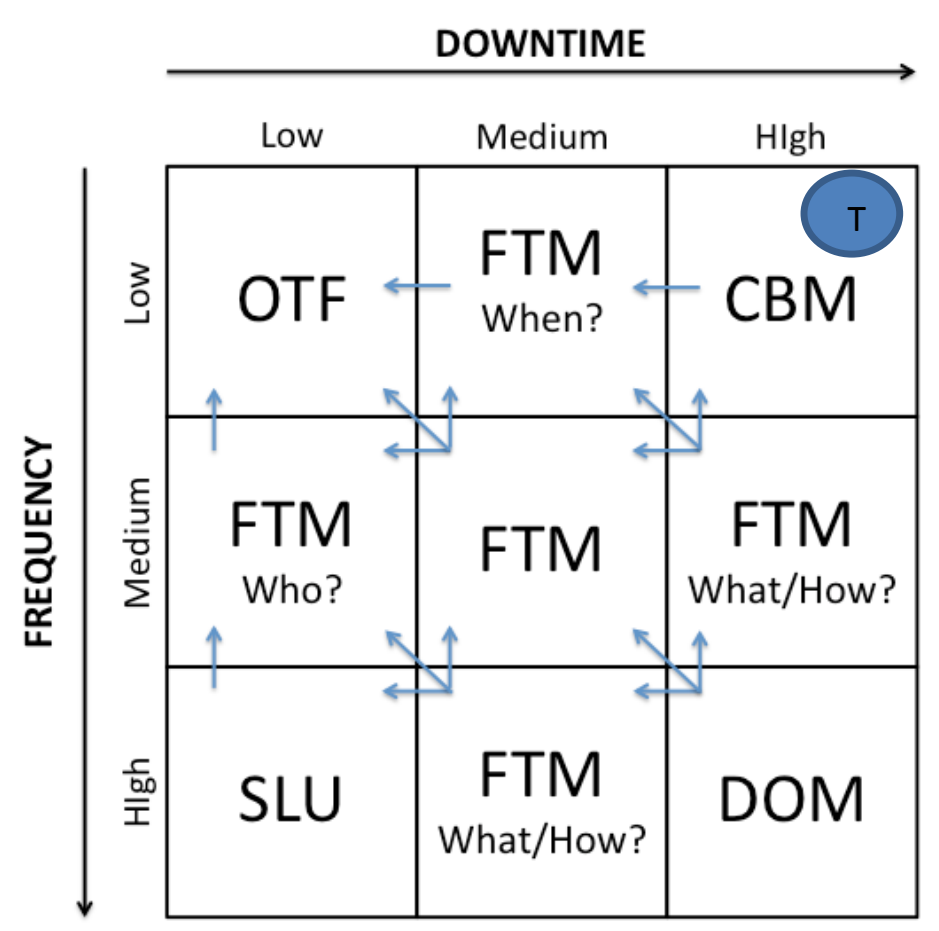

Figure 1 Decision Making Grid (Labib, 2004, 2014)

\subsection{AHP}

The Analytic Hierarchy Process (AHP), developed by Saaty (1980), is a methodology that facilitates the decision making process for complex problem with multiple criteria to consider. According to Ishizaka and Labib (2011a), the AHP has been used in several fields since 1972. There are several reported methods to perform the analysis within AHP. For a review of these methods, the reader can consult Ishizaka and Labib (2011b).

In terms of the state-of-art in the application of AHP in the related fields, AHP has been used as a selection methodology for risk assessment of asset maintenance decision making (Chemweno et al, 2016), in real-time monitoring of offshore processes (Khan et al (2016), in distribution system condition-based maintenance (Shan et al, 2016), and in condition evaluation for power transformer using fuzzy AHP (Sun et al, 2016). Moreover, AHP has been used in combination with fuzzy set in group decision making (Chiao, 2016) and in group decisions (Srdjevic et al, 2016). In addition, it has been incorporated in the assessment of maintainability of desktop software (Pandey et al, 2016), life cycle impact assessment (Hafizan et al, 2016), used for equipment evaluation in a flexible manufacturing system (Nguyen, 2016), and in the evaluation of risk in IT projects (Rodríguez et al, 2016). 
It consists of four stages: problem modelling, pairwise comparisons, priorities calculations, and sensitivity analysis. In the problem modelling stage the team identifies the goal, the criteria and the alternatives to draw the hierarchy (Ishizaka and Labib, 2009)

The second step involves assessment of each node of the hierarchy. It is recommended to do it in pairs to reduce the inconsistency. It is a time consuming technique; however it is relatively easy because it does not require quantitative data. Therefore, a general impression regarding one alternative compared to the other is sufficient. This assessment is done among each of the criteria with respect to the goal, and then among each to the alternatives with respect to each criterion. Such procedure is also called, synthesis, or weight valuation.

In the third step, the global priorities are identified by aggregating (multiplying) the weight valuation of the criteria by the weight valuation of the alternatives, which is performed by multiplying two matrices.

The last step consists of analysing how the global priorities would change if slight modifications were done to the importance of the criteria, which is called sensitivity, or 'what-if' analysis. If the result is consistently the same regarding the changes, it is then concluded that the alternative is robust (Ishizaka and Labib, 2009).

\section{THE POWER TRANSFORMER}

\subsection{General Description}

A power transformer is a liquid-immersed transformer, which depending on its context, is used to step up the voltage of the electricity generated to facilitate its transmission to the distribution substations, or to step down the electricity received from the transmission lines to adequate voltage values for the end users.

Figure 2 shows schematically the main parts (and the subsystems) of a transformer, which are: core (magnetic), coils (electric), oil and cellulose (dielectric), tank (mechanic), cooling system (thermal), bushings and tap changer (accessories), and control cabinet. 


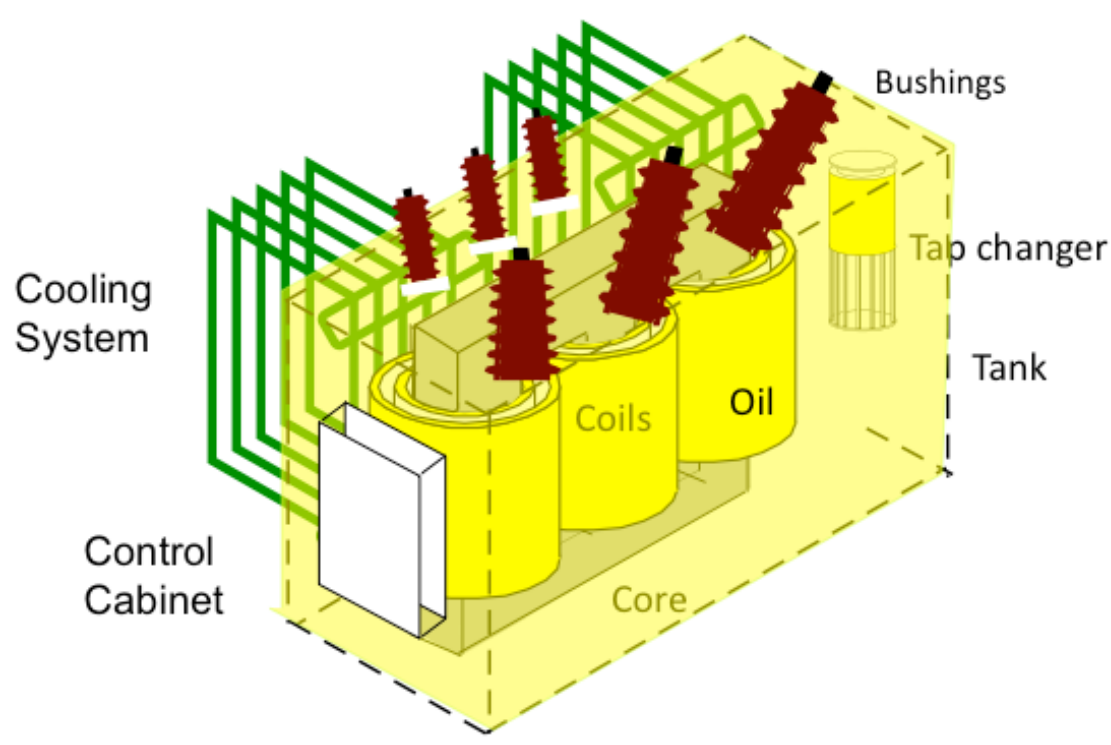

Figure 2 Power Transformer Elements

The transformers are robust static equipment with high reliability, relatively low maintenance and expected service lives of more than 40 years. The design life is 20-25 years considering continuous operation at rated load with an average ambient temperature in the range of 40$65^{\circ} \mathrm{C}$ and adequate maintenance during its entire life (CIGRE \#445, 2009)

Despite the high reliability of a power transformer, the consequences of a failure can be very severe in terms of safety, downtime and equipment loss. The worst case related to safety is a failure that causes an explosion with fire, interrupting the process, losing the equipment, and potentially damaging other assets in the vicinity.

In general, the potential consequences of a transformer failure are:

- SAFETY: Fire and Explosion.

- PRODUCTION: Loss of production, high downtime.

- COST: Expensive large equipment, difficult to replace.

- FACILITIES: Possible damage to other assets.

\subsection{Why Power Transformers Fail?}


Transformer failures are caused by manufacturing defects, inadequate operation conditions and deteriorated processes which accelerate the insulation degradation (IEEE-STD-C57.143, 2012).

The main degradation factors that accelerate the degradation of the transformer insulation and shorten its life are: elevated temperature, water and oxygen. Therefore, the three mechanisms of degradation associated are: pyrolysis, hydrolysis and oxidation. Pyrolysis is the decomposition or transformation of a compound caused by heat. Hydrolysis is the decomposition of a chemical compound by reaction with water. And oxidation is the combination of a substance with oxygen (CIGRE \#227, 2003).

The characteristics of the deterioration processes include sludge accumulation, weakened mechanical strength of insulation materials such as paper wrapped on conductor, and shrinkage of materials that provide mechanical support (CIGRE \#227, 2003).

IEEE-STD-C57.143:2012 provides the parameters to be considered for monitoring the condition of the major components of a power transformer and the available sensors that could be used based on the failure mechanisms. Table 1 lists the information extracted from this standard.

Table 1 Monitored Parameters and Sensors

\begin{tabular}{|l|l|l|}
\hline \multicolumn{1}{|c|}{ CATEGORY } & MONITORED PARAMETER (S) & \multicolumn{1}{|c|}{ SENSOR (S) } \\
\hline \multirow{5}{*}{ Thermal properties } & Top oil temperature & RTD (Resistance Temperature Detector) \\
& Bottom oil temperature & \\
& Ambient temperature & \\
& Simulated winding hot spot & \\
& Control cabinet temperature & \\
\cline { 2 - 3 } & Direct winding temperature & Fibre Optic \\
\hline Cooling system & Fan current & Interposing CT (current transducer) \\
& Pump current & \\
\cline { 2 - 3 } & Pump flow indication & Flow sensor \\
\cline { 2 - 3 } & Cooling contactor & Aux contact \\
\cline { 2 - 3 } & Loss of cooling power & Loss of AC (alternating current) \\
\hline \multirow{5}{*}{ Load } & Load current & Interposing CT \\
\cline { 2 - 3 } & Voltage & VT (voltage transformer) \\
\hline & Tap position & Resistor Board \\
& & Synchro sensor \\
\cline { 2 - 3 } & LTC oil temperature & RTD \\
\cline { 2 - 3 } & LTC motor current & Interposing CT \\
\cline { 2 - 3 } & Limit alarm & Low/high limit \\
\cline { 2 - 3 } & Vacuum bottle fail & Leakage current sensor \\
\cline { 2 - 3 } & LTC control switch & Not in auto \\
\cline { 2 - 3 } & LTC oil level high/low & Level gauge \\
\hline
\end{tabular}




\begin{tabular}{|l|l|l|}
\hline \multicolumn{1}{|c|}{ CATEGORY } & MONITORED PARAMETER (S) & \multicolumn{1}{|c|}{ SENSOR (S) } \\
\hline \multirow{4}{*}{ Main tank } & LTC pressure surge & Sudden pressure relay \\
\cline { 2 - 3 } & LTC pressure relief activated & PRD \\
\cline { 2 - 3 } & LTC oil filter & Flow or pressure \\
\cline { 2 - 3 } & LTC sequence timing & Cam switch \\
\cline { 2 - 3 } & Oil level high/low & Level gauge \\
\cline { 2 - 3 } & Pressure surge & Sudden pressure relay \\
\cline { 2 - 3 } & Pressure relief activated & PRD \\
\cline { 2 - 3 } & Gas accumulation & Gas accumulation relay \\
\cline { 2 - 3 } & Nitrogen pressure & Pressure sensor \\
\hline Conservator & Oil level high/low & Level gauge \\
\cline { 2 - 3 } & Conservator membrane rupture & Membrane leak sensor \\
\hline \multirow{3}{*}{ Gasses (Dissolved } & Hydrogen & Key gas monitor \\
& Carbon Monoxide & Multi gas monitor \\
& Carbon Dioxide & \\
& Ethylene & \\
& Acetylene & \\
& Ethane & \\
\hline Moisture-in-oil & Oxygen & Capacitive sensor \\
\hline Bushing & Dethane & \\
\hline
\end{tabular}

\section{DISSCUSSION ON THE EXISTING MAINTENANCE MODEL}

As shown in the circle located in the top right corner of Figure 1, if the transformer is located in the Decision Making Grid (DMG) to identify the best maintenance strategy, the result will be Condition Based Maintenance (CBM) since the transformer is an asset that rarely fails, but when it does, restoring is function is a time consuming task that consist of using a redundant equipment that may or not be on site, depending on the company policies. 
Notably bodies in the field such as IEC, IEEE and CIGRE support the conclusion that Condition Based Maintenance is the best strategy for the life management of transformers. CIGRE published the guide CIGRE \#227 (2003), where techniques for life management of transformers are provided; the techniques include condition based and condition assessment methodologies.

There is also a guide for transformer maintenance published by CIGRE on February 2011: CIGRE \#445 (2009), which bases the maintenance strategy on the condition assessment of the transformer to decide whether or not more special tests or intensive monitoring is needed before continuing the transformer operation. Time Based Condition Monitoring (TBCM), Condition Based Maintenance (CMB), On-Line Condition Monitoring (OLCM), and Time Based Maintenance (TBM) are the four strategies recommended. It also includes a cost analysis section to determine the best course of action (refurbishment, repair or replacement) when a major work will be necessary for continuing the operation.

The most recent standard IEEE-STD-C57.143 (2012) was published as a guide for applying on-line monitoring equipment to liquid-immersed transformers. The multiple technologies available in the market are compared and suggested according to the failure modes of the equipment and the signals that should be measured to detect the faulty condition. It also includes a methodology to estimate the benefits and the costs associated with the transformer monitoring. This last section of the IEEE standard may be seen as an improvement of a previous guide published by CIGRE \#343 (2008) which also made a review of sensors, data and recommendations for condition monitoring and condition assessment for transformers.

Despite all the standards and common knowledge in the industry regarding the benefits of using condition-based maintenance as the main strategy for this critical equipment, there is still a large population of transformers when its operational condition is unknown or that has a Fixed Time Maintenance (FTM) strategy that does not manage all the potential failures. This situation is more common in plants than electric substations because their main function is production (including power plants).

There are also companies that have already acquired condition-monitoring equipment (for online and off-line testing), but that have not fully utilised it. This situation is evident where such equipment are not commissioned. Even when working properly, the monitoring equipment is 
rarely used for making decisions regarding the maintenance of a transformer. This situation is usually related to the lack of availability of field expertise, data collection, and interpretation.

Other factors that prevent from using the CBM strategy are: the reliability, variety, complexity and cost of the condition monitoring systems, the continuing development of the sensors, the need of an expert to diagnose the transformer, the lack of an integral monitoring system, and the difficulty for deciding the most cost-effective alternative for implementing a CBM system.

\section{FEATURES TO BE CONSIDERED FOR IMPROVING MAINTAINABILITY}

As per previous discussion, it can be concluded that the most important element to improve the maintainability of power transformers is Testability, which is defined in the IEEE-STD-1522 (2004) as "a system design characteristic that allows its operational status to be determined and the isolation of faults to be performed efficiently".

According to the document, the main difference between IEEE-STD-1522 (2004) and MILSTD-2165, is the introduction of the element Diagnosability in the latter. This means that apart from including characteristics to make the system easier to test, it is also necessary to measure "the degree to which faults within a system can be confidently and efficiently identified'. Confidently refers to the ability to detect and isolate the faults unambiguously, and efficiently refers to doing it without waste of resources.

The standard provides measures and metrics to predict the testability of a system. Conceptually, the features to consider for defining the ease of determining and isolating the faults of a system are: the set of all possible functions, failures, failure modes, causes, diagnoses, repairable items, tests, reparations, resources needed (time and cost), and the capability of the system to isolate the fault (IEEE-STD-1522, 2004).

All these factors can be considered for improving the maintainability of a transformer by selecting the best alternative to implement a condition based maintenance regime. Other aspects that need to be taken into account when attempting to select a condition monitoring system are:

From Transformer Perspective 
- New transformer or already on site (age).

- Cost and size of transformer.

- Criticality of transformer (downtime, redundancy, location).

- Type of transformer (single-phase or three-phase).

- Type of oil.

- Operational status.

- Availability of test points.

- Availability of information and tests results from factory.

- Availability of experts to interpret data and diagnose transformer.

From The Monitoring System Perspective

- Reliability, accuracy and resolution of system.

- Requirements for installation and commissioning.

- Information provided.

- Ease for data acquisition and trend analysis.

- Provision of diagnosis or tools for diagnosis.

- Life cycle costs.

- Maintenance and operation requirements.

- Provision of On-line or off-line condition monitoring.

- Supportability.

- IT and remote communication requirements.

- Sensors adequate to operate safely in electric substations.

- Equipment life.

\section{PROPOSED MODEL}

As per all the features listed in section 5 , it can be concluded that one of the factors hindering the use and effective implementation of a CBM system for power transformers is the difficulty for deciding the best alternative for monitoring its condition.

The following model is an attempt by the authors to provide a tool for selecting the most costeffective strategy for monitoring the condition of the transformer. 


\subsection{Structure}

The hierarchy for selecting the best strategy for the monitoring system of a power transformer is shown in Figure 3. It consists of two levels: first level is for the criteria and the second level for the alternatives. The four criteria elements were used as common attributes for comparing all the alternatives.

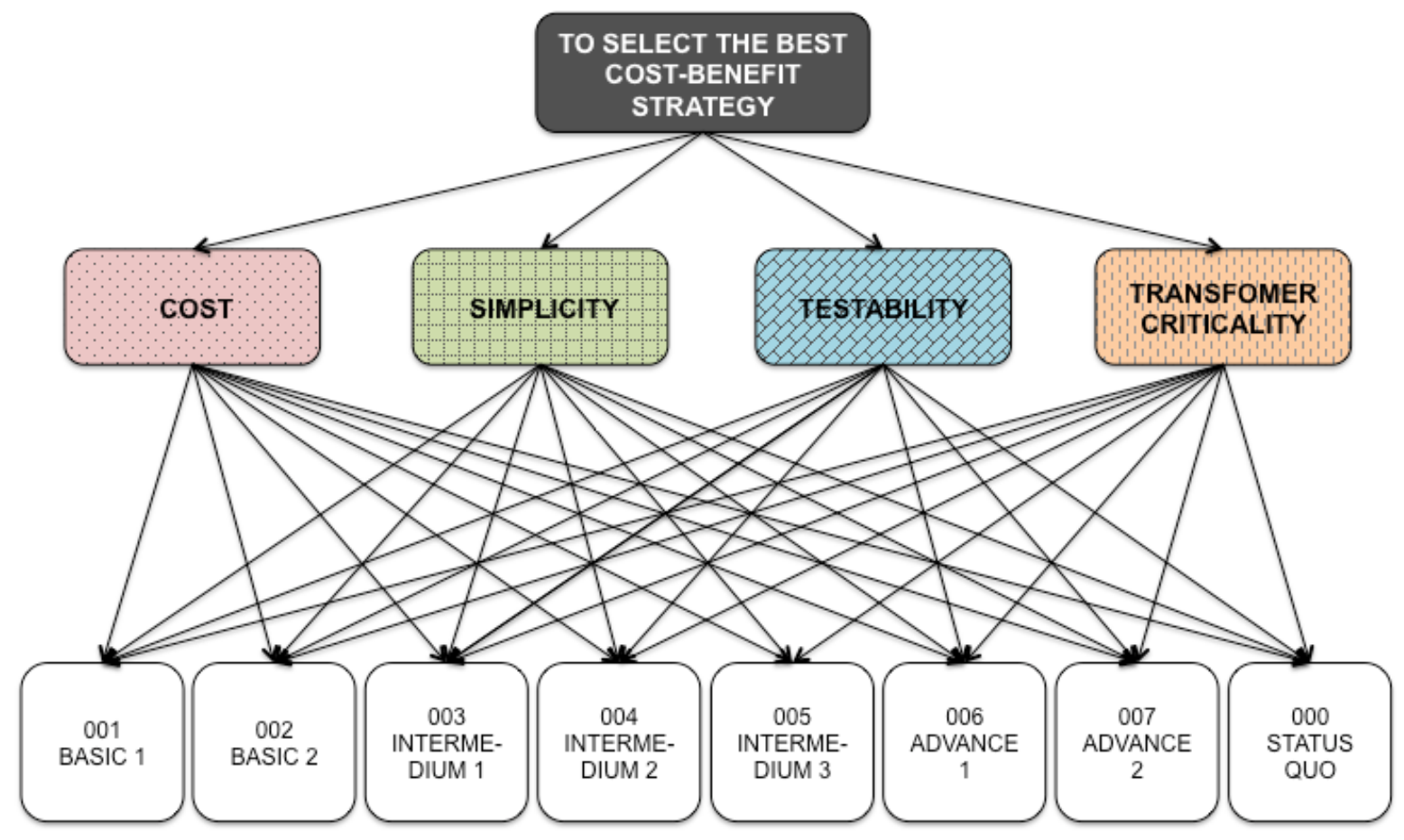

Figure 3 Cost-Benefit Strategy Hierarchy

\subsection{Criteria - Level 1}

This level shows the attributes that are important to evaluate which condition monitoring system is the most suitable for a power transformer. The elements are:

- Cost: It refers to the cost of acquiring, installing, commissioning, operating, and maintaining the condition monitoring system.

- Simplicity: It is how simple the condition monitoring system is for installing, commissioning, operating and maintaining it. 
- Testability: It is defined as the degree to which the operational status of the transformer can be determined and the faults within it can be confidently and efficiently identified and isolated by the condition monitoring system.

- Transformer Criticality: It refers to the degree of which the criticality of the transformer can be reduced by the condition monitoring system, where criticality is a combination of the likelihood and the severity of catastrophic failure. So for example, if a certain transformer which is critical due to its past poor performance, in terms of either its frequent breakdowns or long downtime, then by using appropriate condition monitoring, one would expect an improvement in performance in providing early warning signal that can contribute to its performance in terms of number or duration of breakdowns.

Note that the terms testability and criticality are close but different. So, testability emphasises the 'determination' aspect of the fault and is a design characteristic, whereas criticality is a performance feature in terms of severity and frequency. Also, note that both maintainability and testability are design attributes.

\subsection{Alternatives - Level 2}

As it can be concluded from Table 1, there are many possible combinations for setting a condition monitoring system for a transformer. In the experience of the authors, the elements to be monitored can be grouped in the following categories: OIL (moisture and Key Gas or Multi Gas), OLTC (On-load tap changer), BUSHINGS and OTHERS. These categories provide 23 different combinations of 1 to 4 elements. However, only 7 alternatives were selected for this model according to the experience of the authors. An eighth alternative was added to compare the condition monitoring system with the choice of maintaining the status quo of "no condition monitoring". (see Table 2).

It is very unusual to exclude the monitoring of the oil and the basic parameters included in the "others" category. And, the monitoring of bushings is an expensive and relatively new technique, which is usually selected to complement the monitoring of very critical transformers. The monitoring of the OLTC is decided based on the frequency of use of this element. There are transformers that has a fixed transformation relation and the OLTC is not used, or transformers without it. The "others" category includes the monitoring of the following 
components since collectively they have the same relatively priority as the other elements: thermal properties, cooling system, load, main tank, moisture in oil, and conservator.

Table 2 Hierarchy Alternatives

\begin{tabular}{|l|c|c|c|c|c|}
\hline \multirow{2}{*}{ ALTERNATIVES } & \multicolumn{5}{|c|}{ ELEMENTS INCLUDED } \\
\cline { 2 - 6 } & $\begin{array}{c}\text { OIL } \\
\text { Key Gas }\end{array}$ & $\begin{array}{c}\text { OIL } \\
\text { Multi Gas }\end{array}$ & OLTC & BUSHINGS & OTHERS \\
\hline 001 BASIC 1 & $\mathrm{X}$ & & & & $\mathrm{X}$ \\
\hline 002 BASIC 2 & & $\mathrm{X}$ & & & $\mathrm{X}$ \\
\hline 003 INTERMEDIUM 1 & $\mathrm{X}$ & & $\mathrm{X}$ & & $\mathrm{X}$ \\
\hline 004 INTERMEDIUM 2 & & $\mathrm{X}$ & $\mathrm{X}$ & & $\mathrm{X}$ \\
\hline 005 INTERMEDIUM 3 & & $\mathrm{X}$ & & $\mathrm{X}$ & $\mathrm{X}$ \\
\hline 006 ADVANCE 1 & $\mathrm{X}$ & & $\mathrm{X}$ & $\mathrm{X}$ & $\mathrm{X}$ \\
\hline 007 ADVANCE 2 & & $\mathrm{X}$ & $\mathrm{X}$ & $\mathrm{X}$ & $\mathrm{X}$ \\
\hline 000 STATUS QUO & & & & & \\
\hline
\end{tabular}

\subsection{Assessment of Pairwise Comparisons}

The pairwise comparison was done by the authors according to the experience with the aid of the software Transparent Choice (2014). The process consisted of evaluating the criteria with respect to the goal, and the alternatives with respect to each criterion. In the case study a GSU three-phase transformer with conservator and on-load tap changer (OLTC) in use, and the monitoring of the bushings with the electric method.

The assessment was very straightforward; the software presents all the necessary pairwise comparisons. The score is from 1 to 9 , where 1 represents that both elements are equally important and 9 that the element chosen was nine times more important than the other.

An example is shown in Figure 4. In this case, in terms of testability, the alternative "006 Advance 1" is twice better than the alternative "002 Basic 2". 


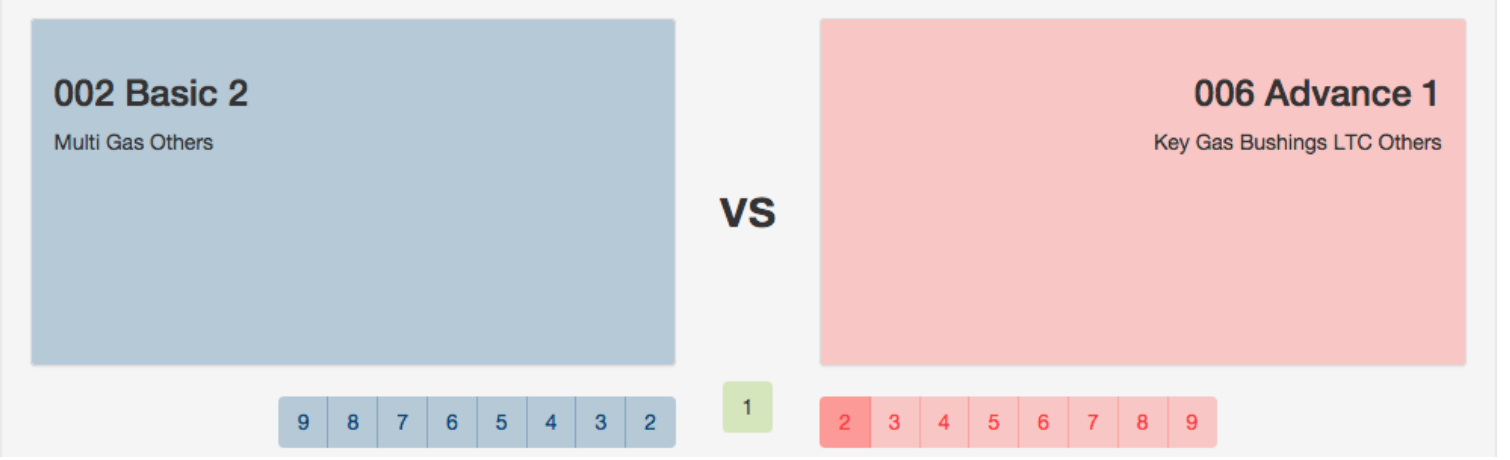

Figure 4 Example of Assessment of a Pairwise Comparison [6]

\subsection{Priorities Calculation}

The priorities of the criteria with respect to the goal are presented in Table 3.

Table 3 Criteria Weights

\begin{tabular}{|l|c|}
\hline \multicolumn{1}{|c|}{ CRITERIA } & RELATIVE IMPORTANCE \\
\hline Transformer Criticality & $43.4 \%$ \\
\hline Simplicity & $19.5 \%$ \\
\hline Testability & $19.5 \%$ \\
\hline Cost & $17.7 \%$ \\
\hline Inconsistency: $1 \%$ & \\
\hline
\end{tabular}

For each criterion, the relative importance of each alternative is presented in Table 4.

Table 4 Assessment of Alternatives from the Criteria Point of View

\begin{tabular}{|c|c|c|c|c|}
\hline & \multicolumn{4}{|c|}{ CRITERIA } \\
\cline { 2 - 5 } ALTERNATIVES & $\begin{array}{c}\text { TRANSFORMER } \\
\text { CRITICALITY }\end{array}$ & SIMPLICITY & TESTABILITY & COST \\
\hline 001 BASIC 1 & 0.0567 & 0.2410 & 0.0498 & 0.2462 \\
\hline 002 BASIC 2 & 0.1115 & 0.1409 & 0.0925 & 0.1127 \\
\hline 003 INTERMEDIUM 1 & 0.0586 & 0.1471 & 0.0697 & 0.1711 \\
\hline 004 INTERMEDIUM 2 & 0.1172 & 0.0853 & 0.1351 & 0.0737 \\
\hline 005 INTERMEDIUM 3 & 0.2076 & 0.0544 & 0.1991 & 0.0487 \\
\hline 006 ADVANCE 1 & 0.1318 & 0.0643 & 0.1351 & 0.0793 \\
\hline 007 ADVANCE 2 & 0.2764 & 0.0383 & 0.2774 & 0.0417 \\
\hline 000 STATUS QUO & 0.0401 & 0.2287 & 0.0413 & 0.2267 \\
\hline Inconsistency & $1 \%$ & $2 \%$ & $2 \%$ & $2 \%$ \\
\hline
\end{tabular}


The global priorities can be calculated by aggregating the weights of the criteria (Table 3) with the weighting of the alternatives for each criterion (Table 4). The global priorities are shown in Table 5.

Table 5 Global Priorities of Alternatives

\begin{tabular}{|l|c|}
\hline \multicolumn{1}{|c|}{ ALTERNATIVES } & PRIORITIES \\
\hline 007 ADVANCE 2 & 0.1889 \\
\hline 005 INTERMEDIUM 3 & 0.1481 \\
\hline 001 BASIC 1 & 0.1248 \\
\hline 002 BASIC 2 & 0.1138 \\
\hline 006 ADVANCE 1 & 0.1101 \\
\hline 000 STATUS QUO & 0.1101 \\
\hline 004 INTERMEDIUM 2 & 0.1068 \\
\hline 003 INTERMEDIUM 1 & 0.0979 \\
\hline
\end{tabular}

From Table 5 it can be concluded that the most preferred option is the alternative "007 Advance 2". This is mostly a consequence of transformer criticality and testability, being the two top ranking criteria.

Section 6.6 presents a sensitivity analysis performed to determine what will be the preferred option if weights of the criteria change.

\subsection{Sensitivity Analysis}

Sensitivity (what if) analysis is a powerful output of the AHP approach. It provides the decision maker with the ability to decide about final outcomes (alternative decisions) if the controlling factors (criteria) change their importance (weight). Such approach provides a dynamic capability in the decision making process and, flexibility in adapting the decision depending on the change of scenarios, or circumstances. It also provides a better understanding of the robustness of the criteria. In other words whether the alternatives are sensitive or not towards a certain criterion.

Figures 5, 6, 7 and 8 shows the what-if analysis for each of the criteria in the following order: cost, simplicity, testability and transformer criticality. The vertical axis represents the score of the alternatives and the horizontal axis represents the weight of the criteria.

It can be observed that with the specified set of weights for the criteria, "007 Advance 2" is the most preferred alternative. It can also be observed from Figure 8 that irrespectively of the weight of the Testability criterion, this option is always preferred. However, from Figures 5, 6 
and 8 it can be seen that if the importance of Cost and Simplicity criteria increases more than $33 \%$ and $35 \%$, respectively, or the transformer criticality is less than $25 \%$, the most preferred option will be the alternative "001 Basic 1", followed very closed by "000 Status Quo".

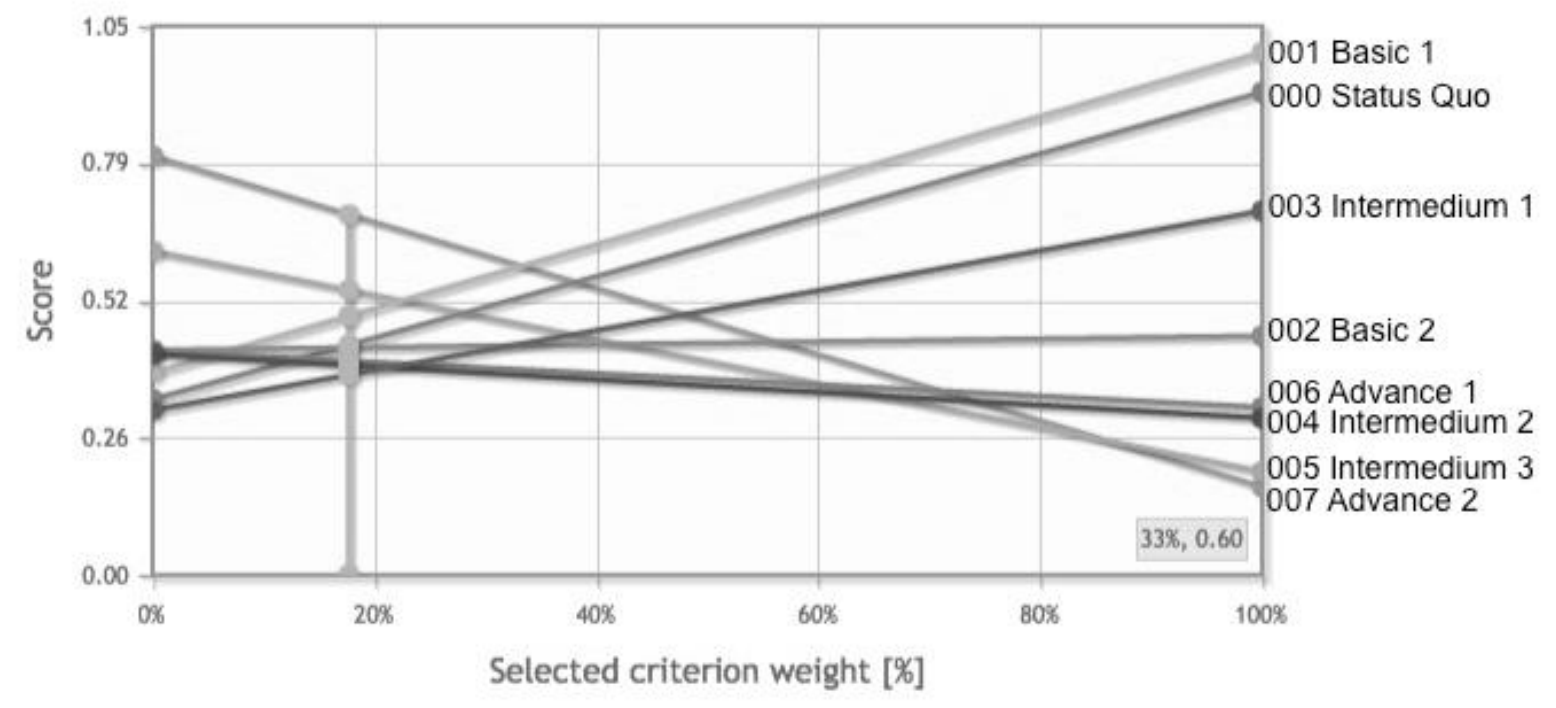

Figure 5 Sensitivity Analysis of Cost

Each figure of sensitivity analysis focusses on measuring the impact on cost-benefit performance of alternatives due to varying the weight of one criterion. Since the weights are in percentages, when the weight of one criterion is increased (or reduced), the weights of the other criteria will have to be adjusted accordingly, i.e., reduced (or increased), to compensate for the change without changing the relativity amongst these other criteria.

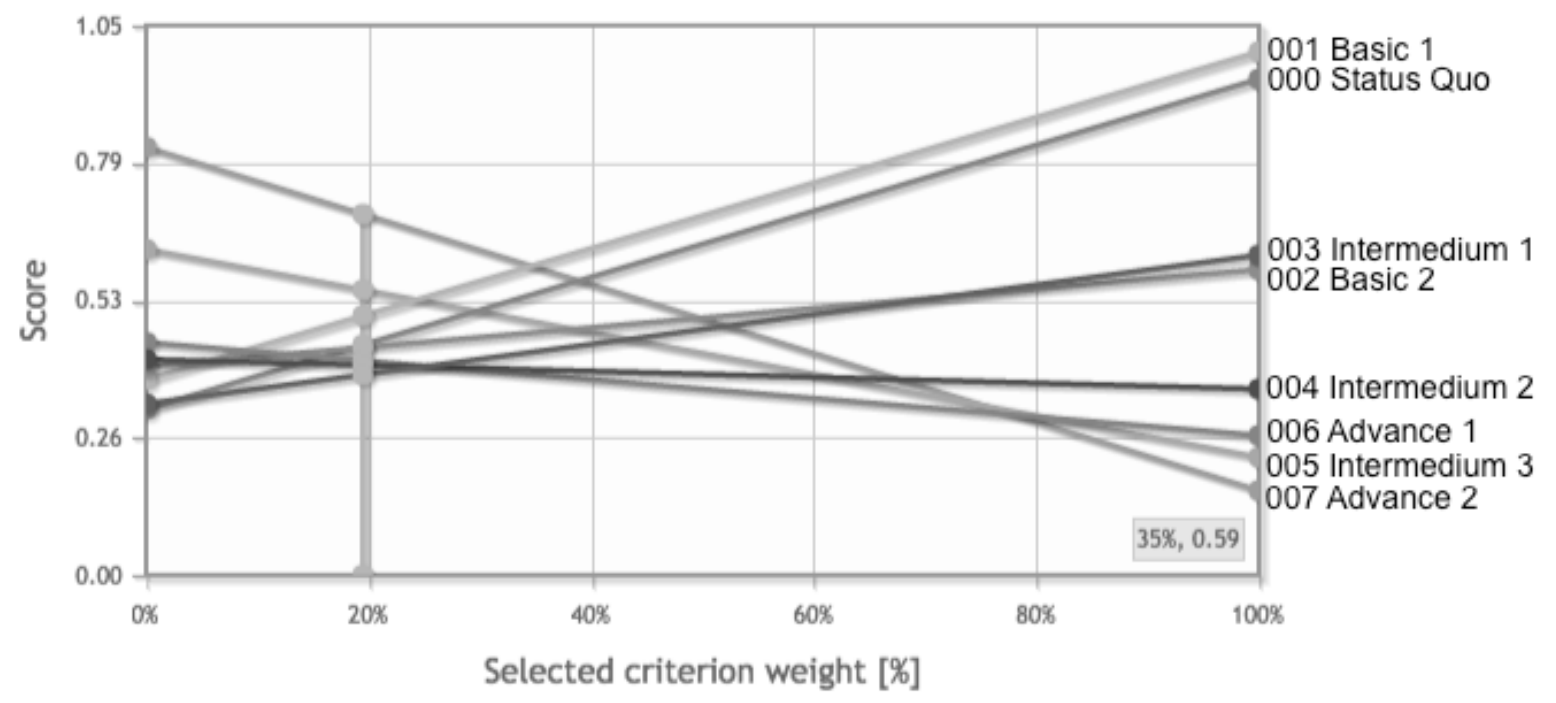

Figure 6 Sensitivity Analysis of Simplicity 


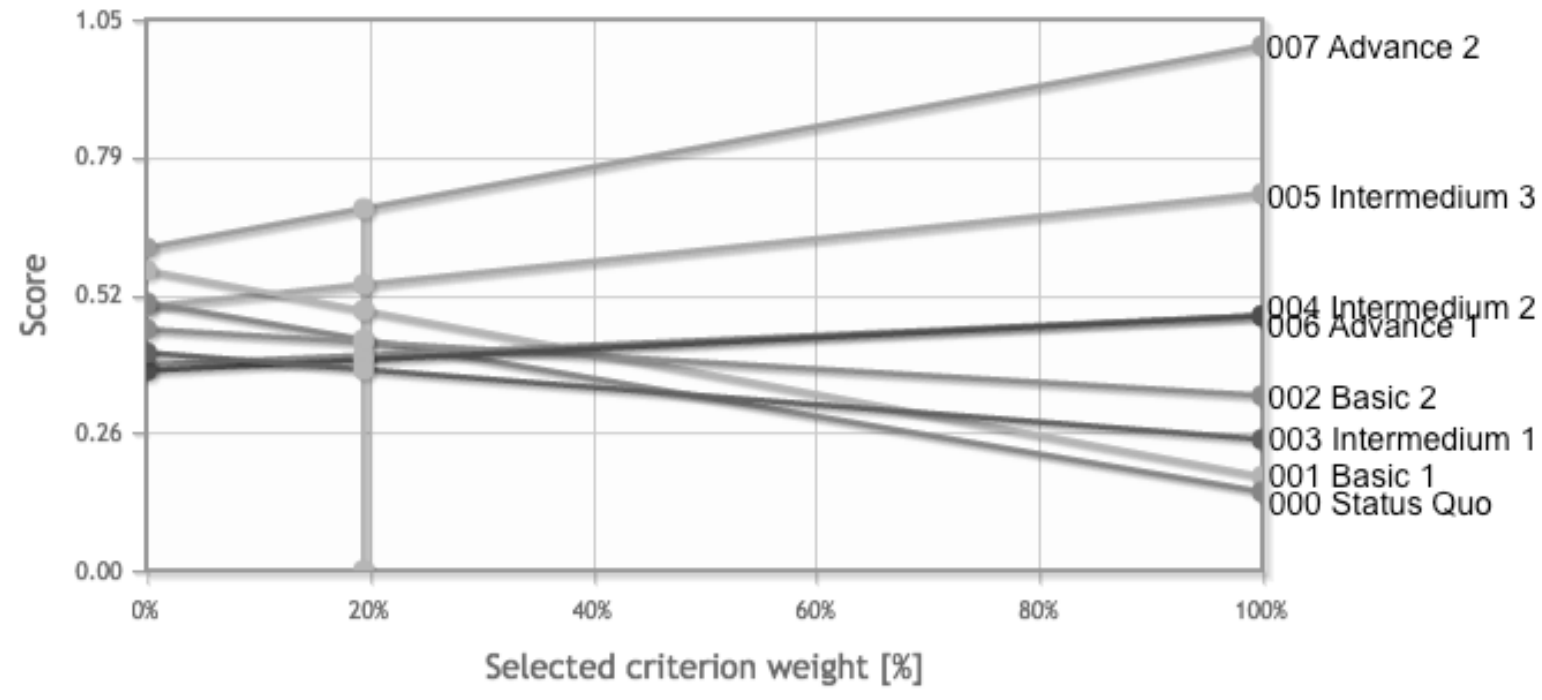

Figure 7 Sensitivity Analysis of Testability

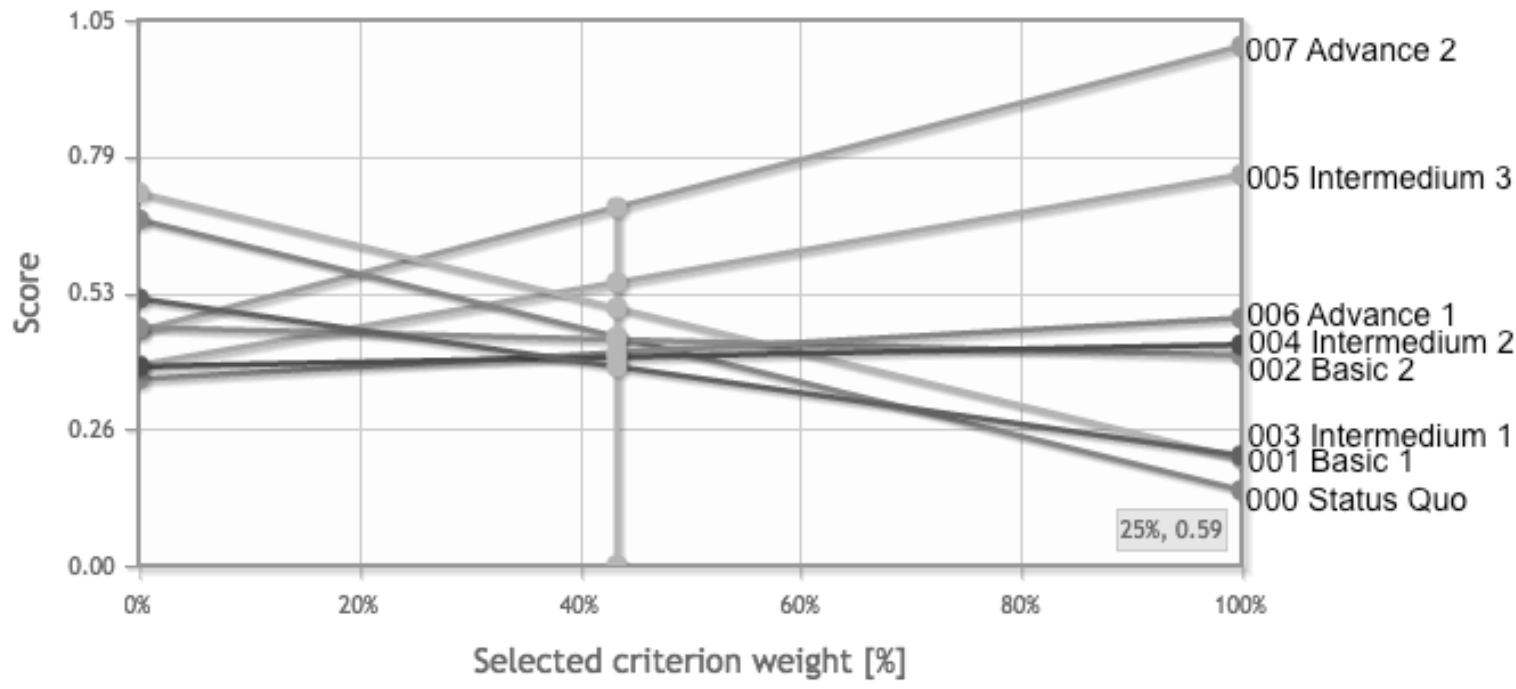

Figure 8 Sensitivity Analysis of Transformer Criticality 


\subsection{Discussion}

The proposed model provides a structured solution for the people in need of deciding the best combination of technologies for condition monitoring of a given type of transformers. It helps to have a better understanding of this complex problem and to decide even when there is lack of quantitative data.

On the other hand, the model can be highly improved if the further considerations are added to the model:

- Complementing the assessment with different stakeholders as per proposed model in (Ishizaka and Labib, 2011).

- Selection of alternatives considering the opinions of more experts in condition monitoring systems.

- Assessing transformer criticality in terms of its two main factors: probability of failure and impact of failure.

- Including the "Supplier Support" criterion, which has proven to be a critical factor when deciding the equipment to acquire.

- Adding a level for assessing the different technologies available on the market.

- Applying the proposed methodology the preferred condition monitoring options for different types of transformer: single-phase, three-phase, with or without LTC, step up or step down transformer, and purpose (generation, transmission or distribution).

\section{CONCLUSIONS}

Although the power transformers are very reliable assets, they are very critical in the electric sector, especially when it is used to step-up the voltage of the electricity generated in a power plant to facilitate its transmission. In this paper, it was identified that the best strategy for a power transformer is condition based maintenance. However, the transformer was not designed with the testability and diagnosability element within it.

As a result of this need, in order to increase the reliability, safety and maintainability level of the transformer, and to reduce the direct and indirect costs of the maintenance, the industry has developed and made available many on-line condition-monitoring technologies for detecting the operational status and identifying its faults (when applicable). 
However, the success for implementing a CBM system depends greatly on selecting the best strategy for monitoring the condition of the system - a complex problem with many variables to consider. This paper presented a model (based on the AHP) for assisting the maintenance managers in the process of deciding which $\mathrm{CM}$ system is the most suitable for increasing the maintainability of their transformers' population.

Based on the failure modes of the transformer, the parameters to be monitored, the available technologies, and the factors that has influence on the maintainers to use their CM systems, a hierarchy of the problem was established. The four criteria selected are: cost, testability, simplicity and transformer criticality. Regarding the alternatives, seven options were described as per the expertise of the authors. The conclusion was that for a three-phase GSU transformer with LTC the recommendation is to monitor the main subsystems of the transformer: oil (with a multi gas monitor), bushings, LTC and others. It was found also that this recommendation does not change if testability is the main criterion. However, if the weights of the other three criteria change, the best decision is to monitor the condition only of the oil (with a key gas monitor) and the others.

The proposed model provides a structured solution for the maintenance decision makers. However, it is recommendable to include the assessment of different stakeholders and add more levels in the hierarchy. Some additional sub criteria may include: current condition of transformer, specific impact of failure, different technologies, supportability level from supplier, and different types of transformers.

\section{REFERENCES}

Chemweno, P., Pintelon, L., Van Horenbeek, A., \& Muchiri, P. (2015). Development of a risk assessment selection methodology for asset maintenance decision making: An analytic network process (ANP) approach. International Journal of Production Economics, 170, 663676.

Chiao, K. P. (2016). The multi-criteria group decision making methodology using type 2 fuzzy linguistic judgments. Applied Soft Computing, 49, 189-211.

CIGRE \#227-2003, International Council on Large Electric Systems, Working Group A2.18, Life Management Techniques for Power Transformers.

CIGRE \#343-2008, International Council on Large Electric Systems, Working Group A2.27, Recommendations for Condition Monitoring and Condition Facilities for Transformers. 
CIGRE \#445-2009, International Council on Large Electric Systems , Working Group A2.34, Guide for Transformer Maintenance.

Dhillon, B. (1999). Engineering Maintainability: How to Design for Reliability and Easy Maintenance, Gulf Pub, Houston, Tex.

Fernandez, O., Labib, A.W., Walmsley, R., D.J. Petty, D.J. (2003), A Decision Support Maintenance Management System: Development and Implementation, International Journal of Quality and Reliability Management, IJQRM, 2003, Vol. 20, No 8, pp. 965-979.

Hafizan, C., Noor, Z. Z., Abba, A. H., \& Hussein, N. (2016). An alternative aggregation method for a life cycle impact assessment using an analytical hierarchy process. Journal of Cleaner Production, 112, 3244-3255.

IEEE C57.43-2012, IEEE Guide for Application for Monitoring Equipment to Liquid-Immersed Transformers and Components.

IEEE-STD-1522 (2004), IEEE Trial-Use Standard for Testability and Diagnosability Characteristics and Metrics.

Ishizaka, A. and Labib, A.W., (2009), "Analytic Hierarchy Process and Expert Choice: Benefits and Limitations", OR Insight, Vol. 22, No.4, pp. 201-220

Ishizaka, A. and Labib, A.W., (2011a), "Selection of New Production Facilities with the Group Analytic Hierarchy Process Ordering Method", OR Insight, Vol. 38, pp. 7317-7325.

Ishizaka, A. \& Labib, A.W. (2011b), Review of the main developments of AHP, Expert Systems with Applications, 38(11), 14336-14345.

Khan, F., Thodi, P., Imtiaz, S., \& Abbassi, R. (2016). Real-time monitoring and management of offshore process system integrity. Current Opinion in Chemical Engineering, 14, 61-71.

Labib, A.W. (1998). "World-Class Maintenance Using a Computerised Maintenance Management System", Journal of Quality in Maintenance Engineering, Vol.1, pp. 66-75.

Labib, A. W. (2004). "A Decision Analysis Model for Maintenance Policy Selection Using a CMMS", Journal of Quality in Maintenance Engineering, Vol.3, pp. 191-202. 
Labib, A. (2014). Learning from Failures : Decision Analysis of Major Disasters, Elsevier Butterworth-Heinemann, USA.

Nguyen, H. T., Dawal, S. Z. M., Nukman, Y., Rifai, A. P., \& Aoyama, H. (2016). An integrated MCDM model for conveyor equipment evaluation and selection in an FMC based on a Fuzzy AHP and Fuzzy ARAS in the presence of vagueness. PloS one, 11(4), e0153222.

Pandey, A. K., \& Agrawal, C. P. (2016). Fuzzy ANP Model to Measure the Maintainability of Desktop Software based on Software Development Factors. Indian Journal of Science and Technology, 9(33).

Rodríguez, A., Ortega, F., \& Concepción, R. (2016). A method for the evaluation of risk in IT projects. Expert Systems with Applications, 45, 273-285.

Saaty, T.L. (1980) The Analytic Hierarchy Process: Planning, Priority Setting - Resource Allocation. McGraw-Hill: New York.

Shan, Z., Wang, H., Ying, G., Zhang, B., \& Xu, J. (2016, August). Multi-objective decisionmaking model for distribution system condition-based maintenance. In Electricity Distribution (CICED), 2016 China International Conference on (pp. 1-5). IEEE.

Srdjevic, B., Pipan, M., Srdjevic, Z., Blagojevic, B., \& Zoranovic, T. (2015). Virtually combining the analytical hierarchy process and voting methods in order to make group decisions. Universal Access in the Information Society, 14(2), 231-245.

Sun, L., Ma, Z., Shang, Y., Liu, Y., Yuan, H., \& Wu, G. (2016). Research on multi-attribute decision-making in condition evaluation for power transformer using fuzzy AHP and modified weighted averaging combination. IET Generation, Transmission \& Distribution.

Tahir, Z., Prabuwono, A.S., \& Burhanuddin M.A. (2008) Maintenance Decision Support System in Small and Medium Industries: An Approach to New Optimization Model, IJCSNS International Journal of Computer Science and Network Security, VOL.8 No.11, 2008 pp. 155-162.

Transparent Choice Sofware, TransparentChoice Ltd, 3 Charles Babbage Road, Cambridge, CB3 OG, United Kingdom, 2014. 